\title{
O ISF-UFS e a formação de professores crítico-reflexivos
}

\author{
Elaine Maria Santos ${ }^{1}$ \\ Rodrigo Belfort Gomes²
}

\section{Resumo}

Lançado em 2012, o programa Inglês sem Fronteiras passou por redefinições de escopo, incluindo, em 2014, a formação de professores como uma de suas metas. Desde o início do programa, com o objetivo de preparar os bolsistas para os cursos presenciais ministrados para alunos e servidores da IES, o Núcleo de Linguas (NucLi) da UFS vem trabalhando com a formação de professores, na perspectiva de preparar os bolsistas para um ambiente que privilegia a formação de professores críticos reflexivos, envoltos em discussões que giram em torno do pós-método, do ensino comunicativo, do letramento crítico e de questões culturais e identitárias associadas ao ensino de uma LE. Assim sendo, é objetivo deste artigo faz̧er um levantamento das ações desenvolvidas no IsF-UFS e analisar a percepção de dois exbolsistas sobre o processo formativo pelo qual foram expostos, tendo sido utilizado, para a pesquisa, questionários. A partir das informações colhidas, as impressões dos professores pesquisados comprovaram uma mudança nas suas concepş̃ẽs sobre lingua e ensino de linguas.

Palavras-chave: IsF-UFS. Professor reflexivo. Formação de professores. Ensino de linguas

\footnotetext{
1 Doutorado em Educação pela Universidade Federal de Sergipe. Professora na Universidade Federal de Sergipe.

2 Mestrado em Letras pela Universidade Federal de Sergipe. Professor do Colégio de Aplicação da Universidade Federal de Sergipe.
} 
Para que o programa Idiomas sem Fronteiras possa ser melhor compreendido, é importante analisá-lo como uma política linguística nacional, exercendo grande impacto nas Universidades Federais do país, que buscam o fortalecimento de políticas linguísticas institucionais. No entanto, para possibilitar uma melhor compreensão do IsF, torna-se essencial uma investigação do seu caráter formador, uma vez que a formação de professores se constitui em uma das principais ações a serem desenvolvidas pelo programa.

É importante destacar que ao ser lançado o programa Inglês sem Fronteiras, em 2012, seu principal objetivo estava diretamente relacionado somente a questões linguísticas, uma vez que, neste primeiro momento, buscava-se a "formação e capacitação de alunos de graduação das instituições de ensino superior para os exames linguísticos exigidos para o ingresso nas universidades anglófonas" (BRASIL, 2012, p. 1). Neste momento, a grande preocupação era a preparação dos alunos para a prova de proficiência TOEFL ITP $^{3}$, de modo a favorecer a internacionalização das IES, por meio dos programas de mobilidade acadêmica difundidos pelo governo federal.

As práticas de formação de professores já se faziam presentes nos NucLis implementados em todo o Brasil; tais ações passaram a ser registradas nos documentos oficiais de regulamentação dois anos após o lançamento do programa. A partir da promulgação da Portaria Normativa $n^{\circ}$. 973/2014, outras línguas estrangeiras foram incorporadas, com a instituição do Programa Idiomas sem Fronteiras. As mudanças foram sentidas não somente no número de línguas contempladas, mas, principalmente na ênfase dada ao papel de formação de professores, junto aos bolsistas do programa. Dessa forma, o objetivo principal do IsF passou a ser o de

propiciar a formação e a capacitação em idiomas de estudantes, professores e corpo técnico-administrativo das Instituiç,ões de Educação Superior Públicas e Privadas - IES e de professores de idiomas da rede pública de educação básica, bem como a formação e a capacitação de estrangeiros em língua portuguesa (BRASIL, 2014, p.1).

O investimento na formação de professores esteve presente nas demais peças legislativas, publicadas a partir de então, como, por exemplo, na Portaria nº 30/2016,

\footnotetext{
3 O TOEFL ITP é um exame de proficiência na língua inglesa, com validade de dois anos, aceito em várias escolas de idiomas como comprovação de proficiência linguística. Desde 2012, vem sendo aplicado nos Núcleos de Línguas do Programa Idiomas sem Fronteiras, como forma de avaliação diagnóstica do nível linguístico dos alunos da IES e como prova de nivelamento para os cursos presenciais oferecidos pelo programa IsF. Trata-se de um exame relacionado à internacionalização educacional, sendo, dessa forma, aceito por diversas universidades anglófonas que exigem, de seus alunos, comprovação de proficiência acadêmica, para que possam ser aceitos em cursos de graduação e pós-graduação.
} 
responsável pela ampliação do programa Idiomas sem Fronteiras. De acordo com esse documento, o IsF passou a ter como objetivo a promoção da "formação inicial dos estudantes de licenciatura em língua estrangeira e a formação continuada de professores de língua estrangeira, para fins específicos de internacionalização nas IES e nas escolas brasileiras" (BRASIL, 2016, p. 18).

Tendo como base a necessidade de formar nossos professores bolsistas para que possam exercer suas atividades no programa, o NucLi da UFS elaborou um projeto de formação de professores, que vem sendo cumprido desde 2013, com reavaliações e modificações, baseadas nos resultados obtidos, bem como nas opiniões e avaliações colhidas junto à equipe. Inicialmente, torna-se necessário situar o programa Inglês sem Fronteiras na UFS.

\section{O programa Inglês sem Fronteiras e a UFS}

O escopo inicial do IsF-UFS contemplava um coordenador geral, cinco professores-bolsistas e dois bolsistas para assuntos administrativos. Com a grande procura para as ações disponibilizadas, com destaque para as inscrições nos cursos presenciais, a equipe aumentou, sendo composta, atualmente, por um coordenador geral, um coordenador pedagógico, seis professores bolsistas e três bolsistas administrativos. Ao todo, o IsF-UFS teve quatorze professores de língua inglesa. Desses, oito participaram das ações formativas, mas já deixaram o programa e atualmente há seis professores em atuação/formação no programa.

As influências do trabalho de formação desenvolvido podem ser percebidas tanto com as avaliações colhidas em questionários e entrevistas quanto com a percepção da coordenação sobre as mudanças verificadas. Os professores bolsistas só podem ficar no programa até um período máximo de dois anos, e após transcorrido este tempo, devem ser automaticamente desligados. Assim, dos oito professores que passaram pelo IsF-UFS, podemos traçar o seguinte perfil: durante o tempo em que estiveram ativos no programa, seis deles eram alunos da graduação, um era doutorando e um era mestre. Desses seis, dois demostraram interessem em prosseguir os estudos e estão hoje inscritos no mestrado. Dos atuais bolsistas, cinco são alunos de graduação e uma foi recentemente aprovada na seleção do mestrado. No tocante a produção científica, há um total dez trabalhos apresentados em 
eventos acadêmicos, produzidos por esses professores, e dois projetos de PIBIC desenvolvidos na IES.

Para acompanhar o processo de formação de professores no NucLi do Inglês sem Fronteiras da UFS, além de uma análise dos pressupostos teórico-metodológicos que deram suporte às ações desenvolvidas, foi feito um estudo documental, seguido da análise de questionários ${ }^{4}$ aplicados a dois ex-bolsistas do programa, nos quais podem ser investigadas suas trajetórias acadêmicas antes, durante e após o IsF. Esses dois professores, referidos como Ana e José ${ }^{5}$, foram selecionados por serem ex-bolsistas do programa e já estarem inscritos no mestrado da UFS.

Nos questionários, os bolsistas responderam perguntas sobre suas concepções de ensino ao iniciarem no programa e ao término dos dois anos, no que se refere ao significado atribuído ao ensino de uma língua estrangeira; e o papel ocupado pela gramática, pelas questões culturais e pela criticidade em aulas de línguas e naquelas ministradas por eles. Ao final, os professores deveriam fazer uma reflexão sobre a influência do IsF em suas vidas acadêmicas e profissionais.

O processo de formação desenvolvido no IsF-UFS pode ser agrupado em três tipos de ações totalmente interconectadas e que ocorrem de forma simultânea, mas que foram aqui divididas por questões didáticas. Dessa forma, são realizados estudos metodológicos, observações de aulas e sessões de feedback, além de workshops. As discussões teóricometodológicas estão pautadas na busca pelo desenvolvimento da reflexão de ações, de modo a privilegiar a formação de um professor reflexivo, consciente de suas ações e capaz de opinar sobre procedimentos em sala de aula, e (re)avaliar práticas desenvolvidas, tanto de forma individual, como coletiva, uma vez que, a partir dessa postura, "pode-se ter uma noção dos problemas e preveni-los diante de situações incertas ou indefinidas que surgem durante o exercício profissional” (SILVA, 2010, p. 38).

\footnotetext{
${ }^{4}$ Foi aplicado um questionário aos dois ex-bolsistas do Programa IsF da UFS, com três blocos de perguntas: (1) Qual a sua visão de ensino, antes de entrar no IsF; (2) Nos primeiros meses em que ensinou no IsF...; (3) Após os dois anos em que esteve no IsF... No primeiro bloco, foram feitas as seguintes perguntas: 1. O que significava ensinar uma língua estrangeira? 2. Qual o papel da gramática? 3. Qual o papel das questões culturais? 4. Qual o papel da criticidade? No segundo bloco, os ex-bolsistas tiveram que responder os seguintes questionamentos: 1. Como preparava suas aulas? 2. Inseria atividades lúdicas? Por quê? 3. Inseria figuras e realia? Por quê? No terceiro e último bloco, as seguintes perguntas foram respondidas: 1. Qual a visão sobre o ensino de uma língua estrangeira? 2. Como passou a ver o ensino da gramática? 3. Como passou a lidar com o as questões culturais? 4. Como passou a ver o papel da criticidade?

${ }^{5}$ Todos os sujeitos envolvidos assinaram o Termo de Consentimento Livre e Esclarecido.
} 
Entre os autores que defendem o estabelecimento de práticas de formação docente voltadas para a reflexão destacam-se Dewey (1933) e Schön (1983), cujos trabalhos reforçam a importância em se investir em ações que busquem o diálogo entre professor, alunos e materiais didáticos, e o docente possa, enfim, sentir-se desobrigado a seguir métodos pré-determinados, refletindo sobre suas ações em sala.

A reflexão crítica sobre a sua própria prática e sobre as práticas dos professores e colegas de disciplina são o ponto de partida para que não exista mais o técnico, reprodutor de modelos, conhecedor e aplicador de regras gramaticais, com proficiência na língua estrangeira próxima à de um nativo (SILVA, 2014, p. 29).

As práticas guiadas pela reflexão, seja ela individual ou coletiva, fazem com que o professor em formação aplique as técnicas aprendidas, experimente outras, descarte outras tantas e se aprofunde naquelas que não foram totalmente compreendidas ou que precisam ser ajustadas.

\section{O NucLi-UFS e as concepções teórico-metodológicas que o sustentam}

A reflexão individual e coletiva foi estabelecida em função dos pressupostos teórico-metodológicos que perpassam as discussões levantadas e o processo de preparação de aulas e materiais. Todo o trabalho de formação desenvolvido no IsF-UFS gira em torno da busca pelo equilíbrio entre o estabelecimento de um ensino comunicativo, sustentado pelos pressupostos da condição do pós-método, privilegiando as brechas ${ }^{6}$ de aprendizagem, conforme destacado por Duboc (2017), para que o letramento crítico pudesse se fazer presente em cada aula ministrada e em cada reflexão conduzida.

O objetivo deste artigo não é o de propor uma extensa revisão da literatura sobre os temas acima elencados e sim o de, ao situar as concepções teóricas defendidas, discorrer sobre os trabalhos de formação desenvolvidos no IsF-UFS, tomando como base a percepção de dois ex-bolsistas do programa, a partir da aplicação de um questionário.

\footnotetext{
${ }^{6}$ Para Duboc (2017), as brechas de aprendizagem são entendidas como todas as oportunidades de discussão que surgem na sala de aula e que não necessariamente foram planejadas pelo professor, mas que devem ser aproveitadas para incentivar a discussão entre os alunos. Como exemplo, podem ser destacadas muitas perguntas feitas pelos alunos, e que podem ser ignoradas pelos professores, por não estarem nos seus planos de aula. Outras brechas de aprendizagem podem ser planejadas, quando o professor percebe que um tópico trabalhado no livro didático, por exemplo, possibilita que outros questionamentos sejam trazidos, fazendo com que o aluno tenha a oportunidade de se posicionar criticamente diante das questões levantadas.
} 
Segundo as pesquisas de Kumaravadivelu (1994, 2001, 2003, 2006, 2012), um dos grandes problemas relacionados às questões metodológicas para o ensino de uma língua estrangeira é a difusão da crença de que existe um método ideal de ensino que deve, consequentemente, ser colocado em prática em sua totalidade. Baseado nas discussões de Prabhu (1990), Kumaravadivelu (1994) defende ser necessário preparar os professores em formação para que possam ser capazes de planejar suas aulas envoltos nas concepções do pós-método ${ }^{7}$. Somente o professor é capaz de decidir sobre quais caminhos devem ser traçados pelos seus alunos, pois cada turma é única e as necessidades educacionais não podem ser desconsideradas quando do planejamento de uma aula. Dessa forma, o conhecimento sobre métodos e abordagens deve ser incentivado, não como forma de propor a seleção de um roteiro fixo a ser empregado e sim como meio de disseminar práticas consolidadas, que possam servir como fonte de pesquisa e apropriação. Os professores, baseados nas necessidades de seus alunos, podem se valer de técnicas de métodos $\mathrm{x}, \mathrm{y}$ ou $\mathrm{z}$, ou até mesmo criar novos tipos de atividades, teorizando sobre suas práticas e praticando sobre suas teorias.

Para Kumaravadivelu (2006), o ensino de uma LE deve estar pautado na busca pelo atendimento de três parâmetros: o da particularidade, através do qual a singularidade de cada contexto é levada em consideração; o da praticabilidade, que defende o estabelecimento de processos de reflexão por parte do professor sobre a situação alvo antes que qualquer ação de planejamento ou execução de aula seja realizada, e o docente seja capaz de teorizar sobre suas práticas e de praticar o que foi teorizado; e o parâmetro da possibilidade, relacionado à pedagogia de Paulo Freire, de modo que as questões de poder e dominação possam ser levantadas e levadas em consideração. Assim, o conhecimento da realidade passa a ser primordial para qualquer ação desenvolvida em sala de aula, devendo essa realidade ser questionada, de modo que os atores envolvidos nas práticas educacionais estabelecidas possam ser cada vez mais críticos e ativos na sociedade.

\footnotetext{
7 A condição do pós-método, como defende Kumaravadivelu (1994, 2001, 2003, 2006, 2012), prevê que o/a professor/a não pode ficar refém de um método de eleição, considerando, assim, que não há um método ideal de ensino a ser seguido. As ideias norteadoras do pós-método giram em torno da defesa do/a professor/a como o/a autor/a de suas aulas, de modo que ele/a não esteja centrado/a em tentar aplicar técnicas específicas. Ao invés de seguir métodos estabelecidos, o pós-método defende que, ao analisar seus alunos, o/a professor/a possa preparar sua aula, incluindo as atividades que julgar essenciais para que seus objetivos sejam alcançados, independente se tais atividades estão em consonância com os métodos X ou Y. O importante é que o autor prepare um plano baseado na sua experiência e nas necessidades dos alunos. Por isso o autor destaca que, no pós-método, o/a professor/a teoriza sobre sua prática e pratica a sua teoria.
} 
A condição do pós-método ${ }^{8}$ é trabalhada nos processos de formação de professores no IsF-UFS, na medida em que os professores bolsistas discutem os textos teóricos sobre esta temática e desenvolvem atividades de preparação de aula baseadas nos três parâmetros elencados, privilegiando-se, assim, o contexto, o processo de reflexão sobre as práticas educacionais empregadas e o estabelecimento de um ambiente crítico-reflexivo ${ }^{9}$, a partir das aulas preparadas e conduzidas em sala.

Comungamos com as ideias propostas por Mattos e Valério (2010), ao defenderem a junção de uma proposta de ensino de LE baseada nas características indutivas ${ }^{10}$ e comunicativas com uma postura educacional que privilegie o letramento crítico, por não as considerar excludentes ou antagônicas. Este pensamento pode encontrar respaldo nos textos de Kumaravadivelu (1994), ao nos depararmos com a defesa pelo estabelecimento de um ensino pautado nos postulados do pós-método, com a priorização de práticas e técnicas contextualizadas e indutivas, envoltas em um meio que privilegia a discussão das questões sociais. Dessa forma, para o autor, a aula do(a) professor(a) de línguas estrangeiras deve, entre outras características, promover a consciência cultural do(a) aluno(a); estar pautada em questões de relevância social; ser contextualizada e privilegiar a autonomia discente, a partir de práticas intuitivas que levem ao desenvolvimento da consciência linguística; e facilitar a interação e negociação entre os participantes.

Para Mattos e Valério (2010), o ensino comunicativo tem como objetivo final proporcionar o aprendizado da língua estrangeira, chegando até o estabelecimento de uma leitura crítica. Uma reflexão aprofundada da sociedade e do posicionamento do indivíduo

\footnotetext{
8 A condição do pós-método é verificada na preparação de aulas dos/as professores/as do Inglês sem Fronteiras a partir do momento em que os/as professores/as são livres para preparar suas aulas a partir de suas experiências e do conhecimento sobre seus alunos. Não há nenhuma orientação para que sejam utilizados os métodos X e Y. Ao estudar a teoria sobre metodologia do ensino de línguas, e ao estudar as suas turmas, os/as professores/as utilizam as atividades que acreditam ser mais apropriadas às necessidades de suas turmas, tendo sempre como objetivo o estabelecimento de resultados positivos frente aos objetivos traçados para as aulas.

${ }^{9}$ Esse ambiente crítico-reflexivo é defendido por Kumaravadivelu (1994, 2001, 2003, 2006, 2012) e outros autores que discorrem sobre o letramento crítico, como Monte Mór (2013), como sendo uma oportunidade para que os alunos sejam sempre levados a questionar as situações tais como são colocadas, sem que seja imposto ao aluno um sentido único ou correto. A palavra chave é questionar, mas o questionamento é feito como forma de problematizar e fazer com que o aluno reflita sobre os temas trabalhados e busque um posicionamento seu diante das questões levantadas, e não uma manifestação de acordo com as opiniões dos professores e/ou colegas.

10 Por características indutivas, referimo-nos às práticas em que o conhecimento, seja ele lexical ou gramatical, por exemplo, não é repassado ao aluno, por meio da explanação de regras e de execução de exercícios mecânicos e descontextualizados. Defendemos o emprego de técnicas que privilegiam a discussão e a construção conjunta do conhecimento. Assim, por exemplo, ao invés de apresentar uma regra gramatical, o professor discute o contexto e apresenta algumas frases, que serão analisadas pelos alunos e, a partir da análise feita, alunos e professores discutem as regras do ponto gramatical em questão.
} 
frente às questões abordadas só pode ser prestigiada quando do estabelecimento do exercício contínuo da problematização, que é defendido pelo letramento crítico.

Cervetti, Pardales e Damico (2001, p. 9) esclareceram a diferença entre leitura crítica e letramento crítico. Para eles, a leitura crítica permite ao aluno fazer inferências sobre o texto, em busca de supostas intenções, e buscando um relacionamento direto com o que é dito. Todas as reflexões estão pautadas no que está no texto e nas lições que dele podem ser inferidas. Já com o letramento crítico, tem-se o extrapolamento do que está escrito, incentivando-se a reflexão contínua sobre o que foi dito e o que não foi dito, com o objetivo de dar a sustentação às ideias defendidas. A discussão ultrapassa os limites do texto, com atividades que levam a problematizações das mensagens que foram assimiladas. Assim, "o sentido textual é sempre múltiplo, contestado, situado culturalmente e historicamente, e construído em meio às diferentes relações de poder"11.

Conforme atesta Jordão (2017), o letramento crítico não se constitui em uma abordagem ou metodologia de ensino, não havendo, assim, nenhum tipo de conflito ao se propor práticas que incluam os princípios do ensino comunicativo e do letramento crítico em sala de aula. Ao comparar a abordagem comunicativa com o letramento crítico, a autora destaca que, na AC, o professor é aquele que tem o domínio do conteúdo a ser ensinado, enquanto que no letramento crítico, o professor é alguém capaz de perceber a multiplicidade de sentidos dos textos, encarando essa fonte de diversidade como algo positivo para a aprendizagem e para as trocas de experiências e opiniões vivenciadas em sala de aula, ensinando aos "alunos a construir sentidos novos a partir das diferentes e variadas possibilidades que se lhe apresentam no mundo, dentro e fora da sala de aula" (JORDÃO, 2013, p. 76).

Diante da discussão teórica acima defendida, e que norteia o direcionamento metodológico empregado nas práticas de formação de professores empregadas no IsFUFS, partimos para a análise de como os estudos de textos teórico-metodológicos, as observações de aulas, sessões de feedback e os workshops foram percebidos pelos dois exbolsistas escolhidos para a pesquisa, e de que forma essas práticas foram vistas em seus processos de formação profissional. Partiremos, então, para a análise dos perfis

\footnotetext{
11 “Textual meaning is always multiple, contested, culturally and historically situated, and constructed within differential relations of power" (Texto original. Tradução nossa).
} 
educacionais dos dois participantes, de suas trajetórias junto ao programa e seus testemunhos sobre a formação docente da qual participaram.

\section{Análise dos perfis educacionais de José e Ana}

José fez todo o ensino fundamental e médio em escolas particulares de Aracaju, iniciando seus estudos superiores no curso de Engenharia Florestal. Após os primeiros semestres finalizados, decidiu migrar para o curso de Licenciatura em Letras PortuguêsInglês, em decorrência de seu interesse pela área de literatura e de ensino de língua inglesa. Paralelamente à graduação de Letras, José começou a ministrar aulas de inglês em um curso de idiomas da cidade, recebendo as primeiras orientações no que se refere à formação de professores, o que não pode ser desconsiderado na análise aqui feita. É importante destacar que nem todos os alunos da graduação em LE estão necessariamente em processo de formação inicial, já que alguns começam a ensinar durante a graduação (SILVA, 2014). Ao sair do programa IsF, José foi selecionado para ensinar inglês em um curso de línguas de renome na cidade e, com o final da graduação, participou da seleção para o mestrado em Letras da UFS, tendo iniciado seus estudos em março de 2018

Durante os dois anos em que esteve no IsF, José esteve presente em todas as ações de formação desenvolvidas, participando dos workshops, sessões de feedback e discussões desenvolvidas semanalmente. Incentivado a pesquisar sobre os temas trabalhados, tendo como campo de pesquisa suas salas de aulas, publicou seis trabalhos, com temas que variavam desde a análise do programa na IES até as questões relacionadas ao ensino da leitura e do desenvolvimento das habilidades orais, com destaque para os cursos baseados em TED Talks ${ }^{12}$ que foram desenvolvidos no IsF-UFS.

Ana, a segunda ex-bolsista analisada nesta pesquisa, também estudou em escola particular na capital do Estado e concluiu o curso de Letras Português-Inglês no final de 2016, ano em que foi desligada do IsF-UFS, por ter cumprido o período máximo permitido para um bolsista. Não tinha experiência prévia com o ensino de língua inglesa e, da mesma forma que José, participou de todas as ações de formação de professores oferecidas, publicando, da mesma maneira que seu ex-colega, seis artigos em eventos acadêmicos

12 Ted é uma série de conferências realizadas na Europa, na Ásia e nas Américas, com duração máxima de 18 minutos, sobre Tecnologia, Entretenimento e Planejamento, e cujos vídeos são difundidos na internet através do site https://www.ted.com/. 
sobre o IsF, destacando a relação entre motivação e o aprendizado de uma LE, as questões inerentes ao programa e os trabalhos desenvolvidos com os English Teaching Assistants ${ }^{13}$ (ETAs) na UFS. Os trabalhos apresentados também cobriram discussões sobre a associação entre ensino comunicativo e letramento crítico, e o processo de preparação de aulas no IsF-UFS, com enfoque naquelas baseadas em TED Talks. Ao sair do programa, em 2016, Ana foi selecionada para ensinar língua inglesa no mesmo curso de idiomas de José, tendo sido aprovada, ainda em 2016, em um concurso para professora substituta de inglês pela UFS. Em 2017, ingressou no mestrado em Educação na instituição, continuando suas pesquisas relacionadas ao ensino de língua inglesa.

\section{Análise do processo de formação de professores no IsF-UFS: concepções relacionadas ao ensino da língua inglesa}

Ao iniciar no programa em 2014, Ana trouxe como referências de ensino de língua estrangeira, as experiências trazidas pela escola onde havia estudado. Assim, acreditava que o ensino de um idioma deveria ser baseado no trabalho extensivo com as regras gramaticais, seguido de listas de exercícios, para que os alunos pudessem assimilar o conteúdo aprendido. A mesma crença era compartilhada por José que, mesmo tendo experiência com o ensino em um curso de línguas, considerava o uso de imagens e realia como supérfluo e sem um propósito que fosse realmente eficaz para o processo de ensinoaprendizagem. Desse modo, tanto Ana como José apresentavam dificuldades em inserir atividades lúdicas e práticas comunicativas em suas aulas, quase não utilizando imagens e jogos, por exemplo.

No que se refere à inclusão de momentos de reflexão em sala de aula, os dois bolsistas compartilhavam da mesma opinião de que o papel da aula de inglês era o de transmitir conhecimentos relacionados à gramática e a fala na língua alvo, não havendo muito espaço para discussões sobre questões culturais ou problematizações das temáticas abordadas, como defende o letramento crítico.

\footnotetext{
13 O programa English Teaching Assistants (ETAs) vem sendo desenvolvido na UFS desde 2014, com a vinda de dois ou três norte-americanos selecionados para uma bolsa Fulbright, em editais destinados aos alunos recém-formados nos EUA e que têm interesse em passar nove meses no Brasil. Os assistentes selecionados são direcionados às universidades brasileiras contempladas pelo programa, e devem divulgar a língua inglesa e trabalhar para o desenvolvimento linguístico de alunos das IES públicas brasileiras, a partir das atividades desenvolvidas, com enfoque em questões culturais.
} 
A gramática tinha papel central e toda a aula de LI [Língua Inglesa] se organizava em torno dela. Eu realmente não refletia muito sobre questões culturais na aula de LI. O máximo que eu considerava como cultura eram as datas comemorativas, mas também não as achava tão relevantes para a abordagem em sala de aula. [...] Bem, eu não costumava refletir sobre criticidade na sala de aula partindo do professor, mas sempre me interessei por isso enquanto aluna, de uma forma geral (Depoimento de Ana, 2017).

Por ser um apaixonado confesso por literatura, e por ter tido uma experiência prévia com o ensino de língua inglesa, ao analisarmos a fala de José, percebemos que ele se preocupava com as questões culturais, principalmente quando giravam em torno da valorização da cultura norte-americana. O objetivo dele, no entanto, não era o de problematizar e levar à discussão crítico-reflexiva e sim o de se posicionar contra as relações de poder e hegemonia dos EUA. Esse fato pode ser comprovado quando constatamos que sua concepção de língua ainda estava relacionada a uma ideia de veículo de comunicação e não de prática discursiva. Podemos inferir da sua fala, que o professor bolsista via na língua uma forma de mostrar ao aluno o poder de dominação exercido pelos Estados Unidos, e não como uma prática discursiva capaz de promover questionamentos e reflexões, sem que a ideia do professor fosse cristalizada entre os alunos.

Acho que só abordava as questões culturais quando eram trazidas pelo livro e/ou com minha curta experiência no exterior. A criticidade, no meu caso, que sempre desconfiei de colonização americana, sempre foi importante, no sentido de jamais colocar a cultura e a língua brasileira abaixo da americana/inglesa (Depoimento de José, 2017).

Com as discussões teóricas, sessões conjuntas de preparação de aula, observações de aula, sessões de feedback e workshops, é notória a mudança de visão no que se refere à percepção da função da língua, do papel desempenhado pelas ações de ensino e do cuidado com a inserção de questionamentos voltados para o trabalho com a cultura e a criticidade. Não basta, no entanto, uma análise unilateral da coordenação do programa em relação a essas mudanças relatadas. É importante que os professores em formação percebam também essa mudança e possam, ciente do seu papel de formador, preparar suas aulas de forma mais crítica e reflexiva. Foi com esse objetivo que aplicamos um questionário aos dois bolsistas e colhemos suas percepções sobre o ensino de LI antes e depois de terem finalizado os trabalhos como professores no programa Inglês sem Fronteiras da UFS.

A percepção de língua e do ensino de uma LE mudou para os bolsistas, o que pode ser percebido em suas falas. A língua passou a ser vista não mais apenas como mera transmissora de conhecimentos, e o ensino de inglês assumiu outras concepções distintas 
da visão anterior de possibilitar troca de informações. Dessa forma, para Ana, "O ensino de LE extrapola a finalidade comunicativa. Através da LE é possível abordar diversos assuntos em sala de aula e educar o aprendiz para ser um cidadão/cidadã mais consciente" (Depoimento de Ana, 2017). José, ao responder o questionário, fez associações não antes feitas sobre o ensino de uma LE e as questões culturais e identitárias inerentes à formação do indivíduo.

Acho que uma nova língua traz consigo uma nova identidade, ou ao menos uma nova forma de se organizar e ver enquanto pessoa. O ensino de uma língua traz ainda consigo não só algo novo, mas uma nova forma de olhar o já existente (a própria língua ou cultura nativa, por exemplo) (Depoimento de José, 2017).

O ensino gramatical, de papel central, anteriormente destacado, passou a ocupar um lugar acessório, sendo visto como importante para a busca pela fluência no idioma, mas não mais essencial para que o ensino ocorra. Ana, por exemplo, passou a ver a gramática como "extremamente importante para o aprendizado da LI, mas não mais no centro das atenções”. Para a professora, “deve haver um equilíbrio entre a gramática, o vocabulário e as habilidades de compreensão e produção escrita e oral, havendo sempre uma adaptação às reais necessidades dos aprendizes" (Depoimento de Ana, 2017). Pensamento semelhante foi compartilhado por José.

A língua deixou de ser vista como mero meio de trabalhar conteúdos linguísticos, assumindo uma postura discursiva, em que as discussões e problematizações assumiam uma posição central nas suas práticas pedagógicas. Percebemos, então, que as concepções relacionadas ao ensino de inglês e sua associação com as questões culturais e de criticidade mudaram ao longo dos dois anos como bolsistas no programa Inglês sem Fronteiras, tendo sido essas mudanças registradas por José e Ana, nos questionários respondidos. Para Ana, as questões culturais passaram a ser vistas "de uma forma muito mais crítica e ampla, que vai além de costumes e tradições, e aborda o modo e as motivações de agir e pensar dos falantes de uma LE, considerando as suas diversas origens e tentando não priorizar uma nação em detrimento de outra" (Depoimento de Ana, 2017). Os bolsistas se mostraram mais preocupados em oferecer oportunidades de debates, afastando-se da ideia de cultura apenas como espaço de celebrações de festividades, que levavam quase que invariavelmente à formação de estereótipos. As problematizações e os questionamentos passaram a ser mais frequentes, evitando-se as apresentações de características culturais, vistas, muitas vezes, como fixas e imutáveis, o que fez com que José buscasse "gerar 
discussões sobre o porquê daquilo e quais as relações com a geografia e a língua" (Depoimento de José, 2017), por exemplo, em toda e qualquer discussão levantada em sala de aula.

Ao ser indagada sobre o papel da criticidade $^{14}$ na preparação de suas aulas, Ana destacou ser este um de seus principais objetivos como professora, passando a refletir sobre o poder transformador que a educação traz para professores e alunos, e se preocupando em assumir a postura de um professor reflexivo, capaz de refletir sobre suas aulas, suas práticas e as atividades propostas, de modo que os alunos possam também assumir posturas crítico-reflexivas.

A criticidade se tornou extremamente presente na preparação e performance das minhas aulas. E não de uma forma a qual é necessário separar um momento para isso; as atividades propostas já a trazem de forma implícita ou explícita. Na minha opinião atual, não é o suficiente nem motivador ensinar/aprender a LI apenas pela LI. É preciso ir além do óbvio, refletir, discutir, provocar o aprendiz para que tenha consciência do seu poder transformador na sociedade, para que assim possa decidir de forma livre e original como pensar e agir (Depoimento de Ana, 2017).

O testemunho de José complementa a fala de Ana, na medida em que exterioriza as discussões levantadas durante o tempo em que esteve em processo de formação no IsF e do cuidado que devemos ter em evitar a colonização de mentes de nossos alunos (LEFFA, 2006; MOITA LOPES, 1996; LIMA, 2008) e abrir espaço para uma verdadeira reflexão crítica em que o pensamento do professor não é o que prevalece, e sim a oportunidade para o diálogo livre.

Acho que a maior mudança foi ter achado vozes que fundamentam e complementam minha opinião nesse assunto. Hoje posso levar para a sala assuntos "polêmicos" e atuais e sei que estou ali formando um cidadão que sabe expressar e defender sua opinião, por mais que eu discorde da mesma (Depoimento de José, 2017).

As falas de José e Ana denotam a percepção que tiveram após os dois anos como bolsistas no programa IsF-UFS. Não se trata apenas de uma análise top-down feita pela coordenação do programa, e sim a fala de quem realmente percebeu uma mudança na sua

14 É importante destacar que os autores deste trabalho utilizaram os termos criticidade, habilidade crítica e reflexão crítico-reflexiva para a descrição das situações ocorridas em sala de aula em que os professores levam os alunos a questionarem as informações contidas nos textos trabalhados, sejam estes verbais e/ou visuais. Assim sendo, os alunos passam a problematizar as informações com as quais entram em contato, refletindo sobre o teor dessas informações e buscando se posicionar criticamente sobre as discussões levantadas, sem que opinião do professor ou do texto seja reproduzida acriticamente. 
perspectiva educacional e atestou estar mais ciente da necessidade de inserir em suas aulas contextos de ensino que privilegiam a intuição e a comunicação, práticas focadas em atividades que levam a debates crítico-reflexivos e uma postura em sala de aula que permite a formação de um professor reflexivo.

\section{Algumas considerações}

Ao analisarmos as ações e resultados do programa Idiomas sem Fronteiras, não podemos nos deter apenas nas possibilidades de desenvolvimento linguístico oferecidas pelo programa, sem uma investigação sobre os processos formativos que acontecem no interior de cada NucLi, considerando-se as especificidades locais e as perspectivas teóricometodológicas compartilhadas entre os integrantes de cada equipe.

O processo de formação de professores desenvolvido na Universidade Federal de Sergipe, no escopo do Inglês sem Fronteiras, está pautado na busca pela construção de um sujeito crítico-reflexivo, que valoriza as discussões que perpassam questões metodológicas e de estabelecimento de contextos educacionais voltados para a criticidade. Assim sendo, são conduzidos debates sobre os pressupostos do pós-método e sobre o estabelecimento de um ambiente comunicativo de ensino e do trabalho com o letramento crítico em sala, valorizando, assim, a formação de um professor crítico-reflexivo. Para Monte Mór, toda proposta educacional precisa estar centrada em conceitos que valorizem a criticidade. Segundo a autora, a habilidade crítica prevê o

desenvolvimento de habilidades de percepção social, de construção de sentidos, do reconhecimento de outras formas de construção de conhecimento (diferentes das tradicionais legitimadas), de promoção de agencia e de cidadania ativa ${ }^{15}$, dentre outras habilidades que despontam e se fazem conhecidas (MONTE MÓR, 2013, p. 45).

Diante do contexto desenvolvido para o trabalho com a formação de professores no IsF-UFS e das ações aqui detalhadas, o objetivo deste trabalho não foi o de apenas detalhar e justificar as ações desenvolvidas a partir do referencial teórico escolhido e das observações feitas pelos coordenadores geral e pedagógico do programa. Buscamos

\footnotetext{
15 Por agência e cidadania ativa, entendemos, respectivamente, a percepção do aluno como sujeito ativo na sociedade, capaz de produzir sentidos e de ser responsável pelos encaminhamentos dados na vida pessoal e na profissional; e o entendimento do papel do aluno na sociedade, ou seja, o modo como ele se vê como cidadão e como ele se percebe no contínuo processo de interação social e de construção da sociedade.
} 
identificar as percepções de dois ex-bolsistas sobre o processo de formação ao qual foram submetidos, a partir da aplicação de um questionário, de modo a verificar a opinião dos mesmos sobre o processo de formação ao qual foram expostos, valorizando, assim, a visão de quem estava sendo formado. A mudança de paradigmas observada pelos estudantes comprovou que suas concepções de língua, de ensino de línguas e de preparação de aulas foram dirigidas para uma perspectiva que valorizava a criticidade, a reflexão e práticas de ensino comunicativas, conforme detalhado nas falas colhidas.

Além dessa autopercepção de mudança de concepções no que se refere às questões educacionais investigadas, tanto José quando Ana conseguiram associar os ganhos profissionais advindos do período em que estavam ligados ao IsF, e de que forma essa experiência impactou ou impactará suas vidas como professores de línguas. Segundo testemunho de Ana,

fica claro perceber que a prática dentro do programa IsF foi positivamente transformadora para mim, de uma forma que apenas $\mathrm{O}$ curso de licenciatura não foi capaz de me oferecer. Ainda hoje, como professora em um curso de idiomas e substituta em uma universidade federal, eu utilizo o meu aprendizado durante o programa para o planejamento de cursos e aulas, e isso me faz sentir mais segura e tranquila como profissional (Depoimento de Ana, 2017).

Para José, o programa IsF significou não somente a oportunidade de crescimento profissional, a partir dos conhecimentos discutidos e compartilhados, mas, principalmente, a sua reafirmação identitária como professor de língua inglesa, anteriormente abalada, mas reafirmada após as experiências vividas.

Tenho minhas dúvidas se continuaria a ser professor de LE se não fosse graças ao IsF. Não falo tanto sobre oportunidades profissionais (e sei que, se hoje trabalho em um curso privado de inglês, é graças à minha experiência no IsF), mas mais sobre minha vontade de continuar ensinando. Acho que só depois do IsF passei a dar mais importância à profissão. Digo: deixou de ser um hobby remunerado para ser uma profissão (Depoimento de José, 2017).

Ao trabalharmos com a formação de professores, seja ela na graduação, em práticas extensionistas ou em programas como Inglês sem Fronteiras, precisamos constantemente comparar as nossas impressões com as sentidas pelos alunos em formação, de modo que nossas práticas possam ser reajustadas e que o processo de formação de professor críticoreflexivo possa ser retroalimentado, uma vez que as mudanças identificadas pelos 
professores supervisores precisam também ser percebidas e discutidas por aqueles que estão em processo de formação, seja ela inicial ou continuada.

\section{Referências}

BRASIL. Portaria n . 1.444, de 18 de dezembro de 2012. Institui o Programa Inglês sem Fronteiras. Diário Oficial da União, seção 1, nº 244, de 19 de dezembro de 2012. Disponível em: $<$ http://isf.mec.gov.br/ingles/images/pdf/portaria_normativa_1466_2012.pdf>. Acesso em: 1 dez. 2017.

BRASIL. Portaria no 973, de 14 de novembro de 2014. Institui o Programa Idiomas sem Fronteiras. Diário Oficial da União, seção 1, no 222, de 17 de novembro de 2014.

Disponível em:

$<$ http://isf.mec.gov.br/ingles/images/pdf/novembro/Portaria_973_Idiomas_sem_Front eiras.pdf>. Acesso em: 1 dez. 2017.

BRASIL. Portaria no 30, de 26 de janeiro de 2016. Amplia o Programa Inglês sem Fronteiras. Diário Oficial da União, seção 1, n 19, de 28 de janeiro de 2016. Disponível em:

<http://isf.mec.gov.br/images/2016/janeiro/Portaria_n_30_de_26_de_janeiro_de_2016_ DOU.pdf>. Acesso em: 1 dez. 2017.

CERVETTI, G.; PARDALES, M. J.; DAMICO, J. S. A tale of differences: comparing the traditions, perspectives and educational goals of critical reading and critical literacy.

Reading Online, v. 4, no 9, 2001. Disponível em:

$<$ http://www.readingonline.org/articles/art_index.asp?HREF=articles/cervetti/index.htm 1>. Acesso em: 22 dez. 2017.

DEWEY, J. Como pensamos. São Paulo: Companhia Editora Nacional, 1933.

DUBOC, A. P. Letramento crítico nas brechas da sala de línguas estrangeiras. In: TAKAKI, N. H.; MACIEL, R. F. Letramentos em terra de Paulo Freire. Campinas: Pontes, 2017.

JORDÃO, C. M. Abordagem comunicativa, pedagogia crítica e letramento crítico: farinhas do mesmo saco?. In: MACIEL, R. F.; ROCHA, C. H. (Org.). Língua estrangeira, formação cidadã. Campinas: Pontes Editores, 2013.

Birds of different feathers: algumas diferenças entre Letramento Crítico, Pedagogia Crítica e Abordagem Comunicativa. In: TAKAKI, N. H.; MACIEL, R. F. Letramentos em terra de Paulo Freire. Campinas: Pontes, 2017.

KUMARAVADIVELU, B. The postmethod condition: (e)merging strategies for second/ foreign language teaching. TESOL Quarterly, v. 28, nº 1, 1994, p. 27-501994. Disponível em: <http://www.bkumaravadivelu.com/articles\%20in\%20pdfs/1994\%20 Kumaravadivelu\%20Postmethod\%20Condition.pdf>. Acesso em: 10 dez. 2017. 
Toward as postmethod pedagogy. TESOL Quarterly, v. 35, nº 4, 2001.

Beyond methods: macrostrategies for language teaching. New Haven; Londres: Yale University Press, 2003.

Understanding language teaching: from method to postmethod. Marhwah: Erlbaum, 2006.

2012.

Language teacher education for a global society. Routledge: Taylor \& Francis,

LEFFA, V. Língua estrangeira hegemônica e solidariedade internacional. In: LEFFA, V.; KARWOSKI, A. M.; BONI, V. de F. C. V. (Org.). Tendências contemporâneas no ensino de inglês. União da Vitória: Kaygangue, 2006, p. 10-25.

LIMA. D. C. de. Vozes da (re)conquista: o papel da cultura no ensino da Língua Inglesa. Polifonia, no 15, 2008, p. 87-107.

MATTOS, A. M. de A.; VALÉRIO, K. M. Letramento crítico e ensino comunicativo: lacunas e interseções. RBLA, Belo Horizonte, v. 10, nº 1, 2010, p. 135-158.

MOITA LOPES, L. P. da. Oficina de lingüística aplicada. Campinas: Mercado de Letras, 1996.

MONTE MÓR, W. Crítica e letramentos críticos: reflexões preliminares. In: ROCHA, C. H.; MACIEL, R. F. Língua estrangeira e formação cidadã: por discursos e práticas. Campinas: Pontes Editores, 2013.

PRABHU, N. S. There is no best method - why? TESOL Quarterly v. 24, 1990, p. 161 176.

SCHON, D. The reflective practitioner: how professionals think in action. Nova Iorque: Basic Books, 1983.

SILVA, P. R. B. S. A prática reflexiva na formação inicial do professor de inglês. Dissertação (Mestrado em Educação). São Cristóvão: Universidade Federal de Sergipe, 2010.

A graduação em Letras-Inglês como formação contínua: desfazendo unilateralidades. Tese (Doutorado em Linguística Aplicada e Estudos da Linguagem). São Paulo: Pontifícia Universidade Católica, 2014. 


\begin{abstract}
Launched in 2012, the English without Borders program has undergone redefinitions of scope, so that, in 2014, teacher training was included as one of its goals. Since the beginning of the program, in order to prepare the in-service teachers for the courses which are taught in the institution, the UFS NucLi has been working with teacher training, in order to prepare them in an environment that privileges the reflective teachers' training, surrounded by discussions about the postmethod, communicative teaching, critical literacy and cultural and identity issues associated with the teaching of a foreign language. Therefore, it is the objective of this article to make a survey of the actions developed in the IsF-UFS and to analyze the perception of two former teachers about the formative process through which they were exposed, using questionnaires. From the obtained results, their impressions confirmed a change in their conceptions about language and language teaching.
\end{abstract}

Keywords: IsF-UFS. Reflective professor. Teacher training. Language teaching

Recebido em: 04/01/2018.

Aceito em: 04/06/2018. 